\title{
Brasil, Argentina e América do Sul ${ }^{1}$
}

\author{
PAUlo Nogueira Batista JR.
}

$\mathrm{N}$ ESTE INÍCIO de século, a situação do Brasil e da América do Sul vem evoluindo para melhor. A melhora pode ter sido modesta, inferior à desejada e à possível, mas parece inegável. Sei que essa avaliação não é compartilhada por muitos daqueles que se opuseram à onda liberal e desnacionalizante que varreu o nosso continente nos anos de 1990. No Brasil, é grande o descontentamento com as políticas econômicas e sociais do governo Lula. O Ministério da Fazenda e o Banco Central continuaram seguindo políticas conservadoras e rotineiras. Houve pouco progresso - se é que houve algum - em termos de distribuição da renda e combate à miséria, em parte porque as restrições impostas pela área econômica do governo dificultaram a implementação das políticas sociais. Em 2005, a crise política e os escândalos de corrupção aumentaram a frustração com o governo e o seu principal partido, o PT.

Mesmo assim, como desconhecer que o quadro econômico e político e os referenciais ideológicos mudaram consideravelmente nos últimos cinco anos? As forças que predominaram na década de 1990 sofreram derrotas em vários países da América do Sul e já não reinam incontestes em lugar algum. $\mathrm{O}$ fracasso, às vezes estrepitoso, da maioria dos países que seguiram fielmente as receitas econômicas do chamado Consenso de Washington abalou conviç̧ões arraigadas e produziu reviravoltas políticas, não raro dramáticas ${ }^{2}$.

O caso mais impressionante foi o da Argentina, que depois de ter atravessado a década como economia-modelo e aliada incondicional dos Estados Unidos, enfrentou crise gravíssima praticamente sem apoio de Washington. A crise começou nos anos finais do período Menem e aprofundou-se com o governo do presidente De la Rúa que, embora eleito com o compromisso de mudar o país, insistiu em preservar, a todo o custo, o regime de rígida vinculação ao dólar estabelecido por seu antecessor. Produziu-se, assim, um verdadeiro desastre econômico e uma crise social e política, que terminou por provocar a renúncia de De la

1 Este ensaio baseia-se, em parte, na apresentação de livro recentemente publicado. A maioria dos temas aqui abordados é discutida com mais profundidade nesse livro, especialmente nos capítulos 3 e 5. Ver Batista Jr., 2005.

2 Uma crítica pioneira e, diria mesmo, profética do Consenso de Washington foi publicada em 1994 por meu pai, o embaixador Paulo Nogueira Batista. O trabalho despertou e continua despertando grande interesse no Brasil e merece ser lido ainda hoje. Batista, 1994. 
Rúa dois anos antes do fim do mandato para o qual fora eleito ${ }^{3}$ No governo Duhalde e, sobretudo, no governo Kirchner, a Argentina reorganizou-se, recuperou a sua autonomia e retomou o crescimento econômico, enfrentando com determinação as pressões dos credores externos, dos países do G7 e do FMI. A "pátria financeira", como é conhecido na Argentina o poderoso lobby políticofinanceiro que prevalecia antes da crise, recolheu-se desmoralizada ao silêncio ou à defensiva.

$\mathrm{Na}$ Venezuela, um presidente nacionalista dividiu o país, mas sobreviveu a um golpe de Estado, apoiado pelo governo dos Estados Unidos, e venceu por larga margem um referendo que propunha o encurtamento do seu mandato. Em outros países, as forças alinhadas com Washington perderam o poder pelo voto ou por movimentos de rua. Na Bolívia, por exemplo, o governo Sánchez de Lozada, fortemente identificado com a agenda dos Estados Unidos, foi derrubado por uma rebelião popular em 2003, a exemplo do que ocorrera com o governo De la Rúa na Argentina, em fins de 2001.

Nos demais países da América do Sul, as mudanças transcorreram, em geral, de forma menos dramática, mas os novos ventos também se fizeram sentir. Partidos ou coligações moderadamente reformistas, de centro ou centro-esquerda, venceram eleições presidenciais em alguns países, derrotando os partidos associados à aplicação das políticas recomendadas pelos Estados Unidos e pelas entidades multilaterais de crédito. Ainda que parcialmente imobilizados por restrições financeiras, vulnerabilidades externas ou inibições e inseguranças de outra natureza, esses governos não têm condições políticas de seguir a cartilha de Washington com a convicção dos seus antecessores. Quando insistem em fazê-lo, enfrentam grandes resistências internas, às vezes violentas. Na maior parte do continente, instalou-se, ou começou a instalar-se, um saudável ceticismo em relação a conselhos externos e supostos consensos econômicos internacionais.

\section{Refluxo de tendências perigosas}

A ideologia da globalização, que esteve em voga durante a maior parte dos anos de 1990, perdeu charme e capacidade de persuasão. As assimetrias e desigualdades sociais associadas ao processo de internacionalização tornaram-se mais evidentes. A proliferação de crises cambiais e financeiras, não só na América Latina como em outras regiões do planeta, abalou a confiança na desregulamentação das economias e na liberalização dos fluxos internacionais de capital. Ampliaramse os movimentos sociais antiglobalização, mesmo nos países desenvolvidos, maiores beneficiários do processo de abertura e integração das economias. O unilateralismo do governo Bush e a exacerbação do nacionalismo dos Estados Unidos, perceptíveis mesmo antes dos ataques terroristas de 11 de setembro de 2001, contribuíram para o refluxo dos discursos pró-globalização. Depois de 11

3 Sobre a crise argentina, ver dossiê publicado em número anterior da revista Estudos Avançados. Ferrer, 2002; Altamirano, 2002; Seitenfus, 2002; e Batista Jr., 2002. 
de setembro, esse refluxo se acentuou. Ficou patente o quanto era ilusória a suposição de que o mundo estaria ingressando em uma "nova era", caracterizada pela diluição das fronteiras e pelo declínio irreversível dos Estados nacionais.

Muitas tendências e idéias perigosas, mas bastante populares e disseminadas na década de 1990, refluíram marcadamente nos últimos cinco anos. Foi o que aconteceu, por exemplo, com a dolarização e outros esquemas de subordinação monetária, que eram considerados benéficos ou inevitáveis por muitos economistas latino-americanos e que chegaram a ser aplicados em alguns países. Com o colapso do regime monetário da Argentina, o relativo sucesso da flutuação cambial do Brasil desde 1999 e o declínio da inflação na América Latina, os propagandistas da dolarização perderam impulso e audiência. Já não são tantos os que se animam a questionar a importância de preservar a soberania monetária e a autonomia na condução das políticas de juros e de câmbio.

Outra iniciativa perigosa que também perdeu impulso nos anos recentes foi a Área de Livre Comércio das Américas (Alca). Desde o início, era bastante evidente que essa proposta de integração hemisférica apresentava muito mais problemas do que benefícios para o Brasil e outros países latino-americanos. Assim como a negociação entre a União Européia e o Mercosul, a Alca pouco oferece, na prática, em termos de acesso adicional a mercados nos setores em que a economia brasileira é competitiva. Além disso, teríamos que nos conformar com grande perda de autonomia em áreas de importância estratégica como tarifas industriais, serviços, investimentos estrangeiros, compras governamentais e propriedade intelectual.

Em 2003, pela primeira vez desde o lançamento da Alca, o Brasil questionou abertamente o modelo de acordo que vinha sendo negociado sob a liderança dos Estados Unidos. Os reflexos se fizeram sentir rapidamente. Tanto a Alca como o acordo Mercosul-União Européia entraram em compasso de espera, refletindo o novo posicionamento dos governos do Brasil e da Argentina e a inflexibilidade dos negociadores norte-americanos e europeus.

Enquanto estancavam as negociações com os países desenvolvidos, avançou gradualmente a integração do Mercosul com o resto da América do Sul e países em desenvolvimento de outras regiões. No âmbito da Organização Mundial do Comércio, o Brasil foi um dos articuladores de uma ampla coligação, envolvendo países em desenvolvimento da Ásia, África e América Latina, que bloqueou a tentativa da União Européia e dos Estados Unidos de diluir as negociações multilaterais para a diminuição das barreiras e subsídios na área agrícola. Paralelamente, o Mercosul concluiu acordos de preferência comercial com países como a Índia e a África do Sul.

Na América do Sul, o elemento central dos esforços de integração é a aliança estratégica entre o Brasil e a Argentina. Ao longo das últimas décadas, foi se consolidando, nos dois países, a percepção de que essa aliança é essencial para fortalecer a nossa autonomia nacional e capacidade de negociação internacio- 
nal ${ }^{4}$. O que se procura é não só consolidar o Mercosul, como também constituir um "segundo círculo concêntrico" mediante a celebração de acordos de livre comércio entre o Mercosul e outros países sul-americanos, como observou Moniz Bandeira ${ }^{5}$. A sinalização é de duplo sentido. De um lado, indica que o Mercosul não se esgota em si mesmo, constituindo o núcleo de um processo maior de integração. De outro, reconhece que a realidade para o Brasil não é tanto a América Latina, mas, sim, a América do Sul ${ }^{6}$.

\section{A política econômica no governo Lula}

É outra, portanto, a orientação brasileira no campo das negociações comerciais. Começamos a superar as posturas atemorizadas, freqüentemente subalternas, que marcaram a política internacional do Brasil nos governos Fernando Collor e Fernando Henrique Cardoso. Não se pode dizer o mesmo da política macroeconômica, infelizmente. Nesse terreno, o Brasil manteve-se atrelado a esquemas e preconceitos que poderíamos ter superado há tempos. Mas, mesmo aqui, há aspectos positivos a ressaltar. A inflação, que parecia escapar do controle em 2002, voltou a diminuir de $2003 \mathrm{em}$ diante. As finanças públicas registraram resultados mais favoráveis, ainda que à custa de uma carga tributária elevada, investimentos públicos deprimidos e escassez crônica de recursos para as políticas de distribuição de renda e combate à miséria.

O mais importante ocorreu na área das contas externas, que vinha sendo um dos pontos fracos da economia brasileira desde o lançamento do Plano Real. Superando todas as previsões, o Brasil passou a registrar, desde meados de 2002, rápido crescimento das exportações e do superávit na balança comercial. Pela primeira vez em muitos anos, e apesar da pesada carga de pagamentos de juros e outras rendas do capital estrangeiro, o déficit no balanço de pagamentos em transações correntes converteu-se em superávit, que chegou a quase $2 \%$ do PIB em 2004 e 2005.

Deve-se observar, a bem da verdade, que esses resultados na área externa não são propriamente mérito nem do governo Lula nem do governo Fernando Henrique, uma vez que não podem ser atribuídos, a não ser muito em parte, a políticas deliberadas de geração ou economia de divisas. O que tivemos, de um lado, foi uma resposta vigorosa, bem mais intensa do que a esperada, das empresas que exportam e das que concorrem com importações ao estímulo proporcionado pela depreciação não-planejada da taxa de câmbio. E, de outro, a ajuda de um cenário internacional em geral bastante favorável, tanto no plano comercial como no financeiro.

4 Sobre o caráter estratégico da aliança Argentina-Brasil, ver Russel e Tokatlian, 2003.

5 Moniz Bandeira, 2004, pp. 113 e 114.

6 Idem, p. 114. 
Evidentemente, ainda é longo o caminho a percorrer. A inflação vem sendo combatida por meio de taxas de juro exorbitantes, freqüentemente as mais altas do mundo e sempre muito superiores não só às praticadas em países desenvolvidos, como também às de todos ou quase todos os países de nível de desenvolvimento comparável ao do Brasil. Os juros altos ameaçam a recuperação da atividade econômica e dos investimentos produtivos, sobrecarregam o custo da dívida pública e danificam as finanças do governo, concentram a renda nacional e contribuem para a valorização exagerada do real em relação ao dólar e outras moedas estrangeiras. A combinação juros altos-câmbio valorizado reduz a taxa de inflação, não há dúvida, mas ao preço de manter a economia crescendo abaixo do seu potencial e de ameaçar o ajuste externo alcançado a duras penas desde meados de 2002 .

Há motivos de sobra para não descuidar da preservação do ajustamento do balanço de pagamentos em conta corrente. As condições internacionais favoráveis do período 2003-2005 não devem durar para sempre. O comércio mundial crescerá provavelmente em ritmo mais lento, as taxas de juro estão subindo nos Estados Unidos e em outros países, há dúvidas quanto à disponibilidade futura de liquidez externa para mercados "emergentes". Os graves desequilíbrios fiscais e de balanço de pagamentos dos Estados Unidos são motivo de preocupação crescente, representando risco ponderável de desestabilização da economia mundial.

Apesar dos resultados comerciais excepcionais e da recuperação das reservas internacionais do país, o Brasil não chegou a consolidar a sua posição externa. É provável que a balança comercial e o resto do balanço de pagamentos em conta corrente comecem em breve a refletir mais claramente os efeitos perniciosos da acentuada valorização cambial ocorrida em 2004 e 2005. Continuam insuficientes as reservas do país, que constituem instrumento indispensável de defesa em situações de desequilíbrio das contas internacionais. O prazo médio da dívida externa é relativamente reduzido, sendo portanto expressivos os vencimentos de principal a cada ano. Além disso, há excessiva liberdade de ingresso e de saída de capitais, problema agravado pela liberalização das normas cambiais em março de 2005. Tudo isso contribui para tornar a economia suscetível a turbulências cambiais e financeiras que dificilmente poderão ser acomodadas pelo simples funcionamento do regime de flutuação cambial.

\section{Argentina: uma política econômica audaciosa}

Em matéria de política econômica e relações com os credores e o Fundo Monetário Internacional, a Argentina de Kirchner tomou um rumo completamente diferente. O presidente argentino resolveu seguir, em diversas áreas, políticas opostas às recomendadas por Washington e aceitas, sem maiores contestações, pelo Brasil de Fernando Henrique e Lula.

$\mathrm{O}$ aspecto mais polêmico foi o tratamento conferido pelo governo Kirchner à dívida pública que estava em moratória desde fins de 2001. A Argentina manteve a moratória por prazo indefinido e apresentou a seus credores um contrato 
de adesão, numa base take-it-or-leave-it. Sustentou a sua posição contra grande pressão do exterior. Suportou muitas ameaças e previsões sombrias. No final, a grande maioria dos credores resolveu take it. Foi um triunfo político para Kirchner. A adesão dos credores acabou superando as expectativas, chegando a $76 \%$ da dívida em moratória. O deságio médio foi de quase $75 \%$, situando-se muito acima do alcançado em reestruturações recentes de outros países que suspenderam o pagamento da dívida.

O sucesso da Argentina nessa questão resultou da combinação de coragem e competência que caracteriza não só o tratamento da dívida, mas o conjunto da sua política econômica. O desempenho da economia argentina tem sido fora do comum, superando o do Brasil por larga margem. O PIB aumentou nada menos que 9\% em 2004 depois de ter crescido 8,8\% em 2003. Já a economia brasileira registrou crescimento de $0,5 \%$ em 2003 e de $4,9 \%$ em 20047 . Para 2005, o FMI prevê crescimento de 7,5\% na Argentina e de apenas 3,3\% no Brasil ${ }^{8}$. A expansão da Argentina tem sido liderada por vigorosa retomada dos investimentos produtivos, o que aumenta as chances de que o processo venha a se sustentar ao longo do tempo.

Apesar da rápida expansão da economia, a inflação foi razoavelmente controlada e o balanço de pagamento registrou superávits em transações correntes. Medida por um índice de preços ao consumidor, a taxa de inflação média anual na Argentina caiu de 25,9\% em 2002 para 13,4\% em 2003 e 4,4\% em 2004. A previsão do FMI é que ela suba para cerca de 9,5\% em $2005^{9}$.

É verdade que a Argentina está retomando o terreno perdido durante a recessão do período 1999-2002. A ressalva é válida, especialmente para a fase inicial da recuperação. Mas não se deve perder de vista o essencial: a Argentina não teria alcançado esses resultados se estivesse seguindo as políticas preconizadas pelo FMI ou (o que daria no mesmo) inspirando-se no exemplo do Brasil.

O FMI recomendou insistentemente que o governo argentino aumentasse as metas de superávit fiscal primário para níveis próximos, em termos de percentagem do PIB, às adotadas pelo Brasil. O ministro da Economia, Roberto Lavagna, não aceitou. A Argentina fixa metas de superávit primário que ela considera compatíveis com o crescimento da economia e outros objetivos do governo. Esse foi um dos princípios que orientaram a bem-sucedida reestruturação da dívida externa pública.

Além disso, o governo Kirchner não seguiu o figurino do FMI em matéria de política monetária e cambial. As taxas de juro de curto prazo na Argentina têm sido sempre muito inferiores às brasileiras. Em termos reais, chegam a ser negativas em alguns períodos. A Argentina busca, além disso, manter um câmbio depreciado e competitivo. O Banco Central vem seguindo um regime de flutuação

7 International Monetary Fund, 2005, apêndice estatístico, tabela 6.

8 Idem, ibidem.

9 Idem, apêndice estatístico, tabela 11. 
administrada, com intervenções no mercado cambial para conter a tendência de apreciação do peso. Essas intervenções são freqüentemente esterilizadas, por meio de operações de mercado aberto ou outros mecanismos. Com taxas de juro internas moderadas, o custo fiscal de acumular reservas internacionais não é proibitivo, como no Brasil.

A Argentina também não tem preconceito contra controles de capital. Restrições à entrada de capitais especulativos ou de curto prazo têm sido aplicadas com freqüência para ajudar a conter a valorização do peso e reduzir a vulnerabilidade externa do país.

Em resumo, a política econômica na Argentina é ousada e não segue fórmulas convencionais. É claro que as circunstâncias brasileiras são muito diferentes. A ninguém ocorre sugerir que o Brasil simplesmente imite a Argentina no tratamento da dívida ou em outros aspectos da política econômica. Não obstante, permanece o fato de que a experiência argentina em 2003-2005 contrasta de maneira notável - para não dizer constrangedora - com o conservadorismo rotineiro da política econômica brasileira.

\section{A aliança Argentina-Brasil}

Esse comportamento divergente no campo econômico-financeiro teve algumas conseqüências desagradáveis para o relacionamento bilateral. A equipe econômica brasileira parecia temer que os conflitos da Argentina com os países desenvolvidos, especialmente no tema da dívida, pudessem "contagiar" a posição do Brasil nos mercados financeiros. Em alguns momentos, pareceu evidente o esforço da área econômica do governo de se diferenciar dos vizinhos argentinos. O governo Kirchner, por sua vez, mostrou-se ocasionalmente insatisfeito e ressentido com a omissão ou o apoio morno do governo Lula nas fases mais difíceis da sua relação com os credores e o Fundo. Evidências de comportamento pouco solidário e até oportunista, da parte de integrantes da equipe do ministro Palocci, chegaram a provocar protestos argentinos.

Mas o pior parece ter passado. O sucesso da Argentina na reestruturação da dívida, que em nada se deveu a apoio brasileiro, deve ter inclinado o governo Kirchner a dar menos importância à tibieza do governo Lula em assuntos econômico-financeiros. Note-se, também, que durante todo esse período os dois países continuaram cooperando em várias questões de importância fundamental. Essa cooperação precisa ser preservada e aprofundada.

Refiro-me em especial às negociações comerciais. Não se deve imaginar que conseguimos afastar, em definitivo, o espectro de acordos desiguais com os Estados Unidos e a União Européia. Washington e Bruxelas não desistiram de abrir espaço para seus bens industriais, serviços e investimentos na América do Sul. O que nos ajuda, por enquanto, é a reduzida disposição dos norte-americanos e dos europeus de fazer concessões nos temas de nosso interesse, em especial a sua relutância em abrir mercados às nossas exportações de bens agrícolas e de outros produtos em que somos internacionalmente competitivos. Não fosse isso, 
maior seria o risco de os países do Mercosul serem induzidos a abdicar de diversos instrumentos de política econômica e, no limite, da possibilidade de desenvolver um projeto autônomo de desenvolvimento, em troca de concessões pontuais para o agronegócio e alguns outros setores exportadores.

Por outro lado, não se deve subestimar a influência de forças domésticas predispostas ao alinhamento com os países desenvolvidos, em especial os Estados Unidos. Em negociações como as da Alca e com a União Européia, reaparecem constantemente situações em que os países desenvolvidos acenam com vantagens e concessões localizadas, sem grande significado do nosso ponto de vista nacional ou regional, mas que podem ser extraordinariamente importantes para determinados grupos de empresas exportadoras. Esses grupos têm, freqüentemente, grande influência no governo, ou em certas áreas do governo, nos meios de comunicação e no parlamento. Arma-se então um circo para subordinar os interesses mais amplos dos países às prioridades estreitas deste ou daquele setor da economia. Assim, os nossos negociadores são sempre forçados a travar uma guerra em dois fronts. Diferentemente do que às vezes se imagina, o front interno costuma ser o mais perigoso.

Por esses e outros motivos, o Brasil precisa conduzir com cuidado as suas relações com a Argentina e os demais países sul-americanos. Sempre existirá o risco de que sejam reavivadas antigas disputas e rivalidades. Diferenças de opinião e de situação nacional são normais e ocorrerão inevitavelmente. Mas não se deve permitir que essas divergências sejam magnificadas por redes de intrigas, prejudicando os nossos objetivos estratégicos.

A quem interessa afastar Argentina e Brasil? Nos dois países, há grupos influentes e identificados com a agenda de Washington que vêem com desagrado a aproximação entre argentinos e brasileiros. Esses grupos eram hegemônicos nos anos de 1990. Agora, contudo, o quadro é outro. A mudança foi (como sempre) mais dramática na Argentina do que no Brasil. Os argentinos passaram do alinhamento automático aos Estados Unidos ("relações carnais" na infeliz expressão de um ministro do governo Menem) para uma posição declaradamente nacionalista.

O Brasil, tipicamente mais cauteloso e pragmático, oscilou bem menos. Na década de 1990, não foi tão longe na subordinação aos Estados Unidos e ao chamado Consenso de Washington, mesmo nos piores momentos. No governo Lula, a despeito do conservadorismo da política econômica, a política externa começou a mudar. Acentuou-se a preocupação com a autonomia nacional e com a recuperação da iniciativa do país em matéria de relações internacionais. Tudo isso, é claro, sem os esplêndidos rompantes quixotescos dos nossos aliados argentinos.

Apesar do pragmatismo cauteloso da política externa, muitos resistem à mudança, inclusive dentro do governo. Assim, tudo tem que ser feito com grande habilidade. Um erro os defensores brasileiros da aliança com a Argentina e outros vizinhos certamente não cometerão: o de cair na armadilha de adotar poses e comportamentos de "líder da América do Sul". 


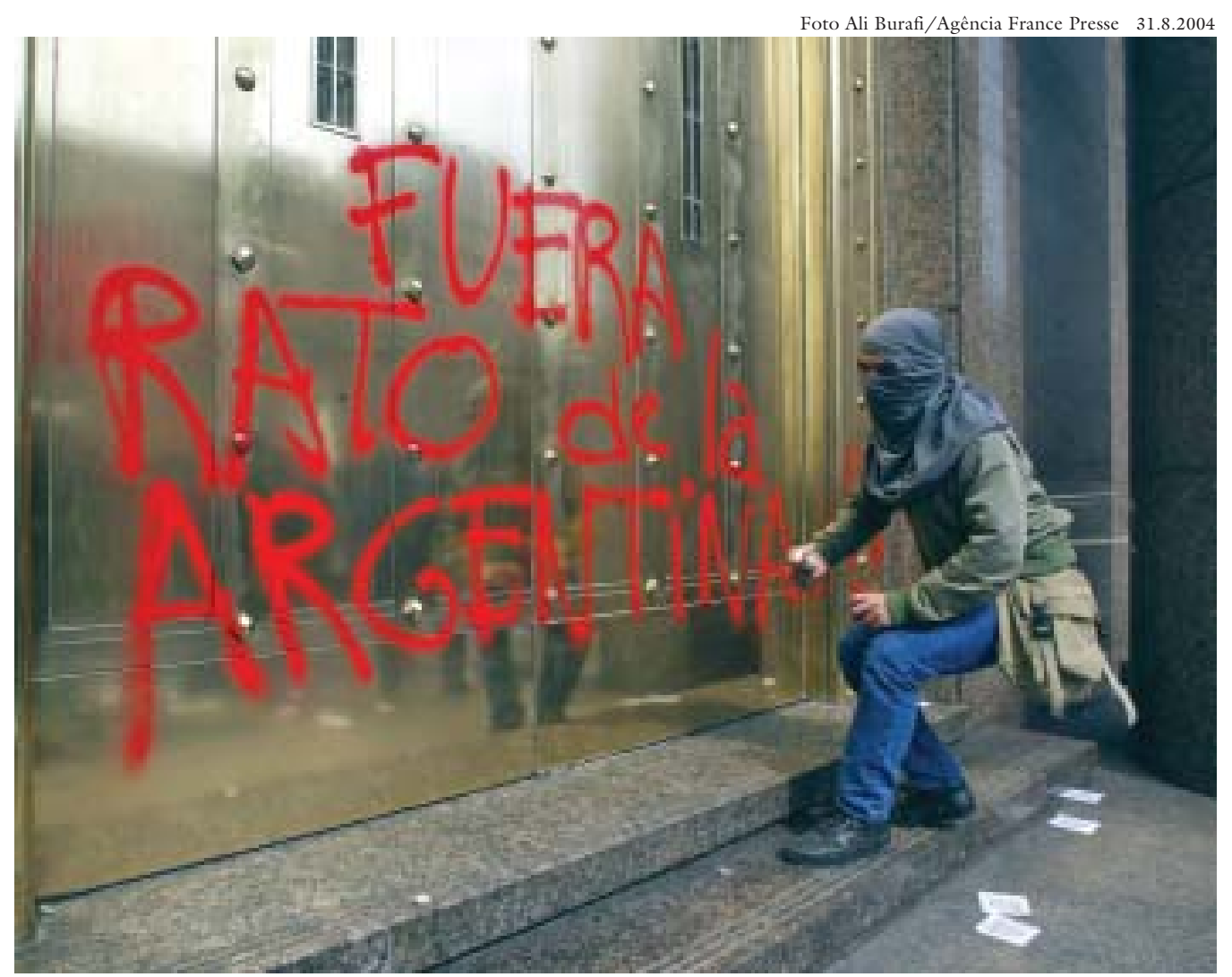

Manifestação contra a presença na Argentina do diretor do FMI, Rodrigo Rato.

Referências bibliogáficas

ALTAMIRANO, Carlos. "Quo vadis Argentina?”, Estudos Avançados, vol. 16, n. 44, jan.-abr. 2002.

BATISTA, Paulo Nogueira. "O consenso de Washington e a visão neoliberal dos problemas latino-americanos". Em LIMA SOBRINHO, Barbosa et alli. Em defesa do interesse nacional: desinformação e alienação do patrimônio público. São Paulo, Paz e Terra, 1994 (esse trabalho foi republicado, sob o mesmo título, pelo Programa Educativo Dívida Externa - Pedex, Caderno dívida externa, n. 6, set. 1994). abr. 2002 .

“"Argentina: uma crise paradigmática”, Estudos Avançados, vol. 16, n. 44, jan.-

O Brasil e a economia internacional: recuperação e defesa da autonomia nacional. Rio de Janeiro, Campus/ Elsevier, 2005.

FERRER, Aldo. "Argentina e globalização", Estudos Avançados, vol. 16, n. 44, jan.abr. 2002 .

INTERNATIONAL MONETARY FUND. World Economic Outlook: Building Institutions, Washington D.C., set. 2005 (www.imf.org).

MONIZ BANDEIRA, Luiz Alberto. As relações perigosas: Brasil-Estados Unidos (de Collor a Lula, 1990-2004). Rio de Janeiro, Civilização Brasileira, 2004. 
RUSSEL, Roberto e TOKATLIAN, Juan Gabriel. El lugar de Brasil en la politica exterior Argentina. Buenos Aires, Fondo de Cultura Económica, 2003.

SEITENFUS, Ricardo. "Metamorfoses argentinas: da prata ao caos", Estudos Avançados, vol. 16, n. 44, jan.-abr. 2002.

RESUMO - ESTE trabalho discute alguns aspectos da evolução econômica recente do Brasil, da Argentina e de outros países da América do Sul. Tendências econômicas e intelectuais perigosas, tais como a "globalização", o chamado Consenso de Washington, a dolarização e as negociações da Alca (Área de Livre Comércio das Américas), perderam ímpeto e a América do Sul está se movendo gradualmente na direção de um posicionamento mais independente na condução das suas política econômicas e internacionais. As mudanças foram muito mais significativas na Argentina do que no Brasil e isso se tornou fonte de alguma tensão entre os dois principais países sul-americanos. Não obstante, uma aliança estratégica entre Argentina e Brasil continua sendo a pedra angular da integração da América do Sul.

PALAVRAS-CHAVE: Política econômica, Política externa, Negociações comerciais, Relações Argentina-Brasil.

ABSTRACT - THIS PAPER discusses some aspects of the recent economic evolution of Brazil, Argentina and other South American countries. Dangerous economic and intellectual trends, such as "globalization", the so-called Washington Consensus, dollarization, and FTAA (Free Trade Area of the Americas) negotiations, have lost momentum and South America is moving gradually towards a more independent stance in the conduct of its economic and foreign policies. Changes have been much more significant in Argentina than in Brazil and this has become a source of some tension between the two major South American countries. Nevertheless, a strategic alliance between Argentina and Brazil remains the corner stone of South American integration.

KEr-WORDs: Economic Policy, Foreign Policy, Trade Negotiations, Argentina-Brazil Relations.

Paulo Nogueira Batista Jr. é economista, professor e pesquisador da Fundação Getúlio Vargas em São Paulo. Foi pesquisador-visitante do Instituto de Estudos Avançados da Universidade de São Paulo. @ - pnbjr@attglobal.net

Recebido em 17.10.05 e aceito em 22.10.05. 